International Journal of Biology, Pharmacy and Allied Sciences (IJBPAS) 'A Bridge Betueen Caboratory and Q Qundor' WWW.jibpas.com

\title{
HEALTH BENEFITS AND NATURAL MANIFESTATION OF AFLOTOXIN IN PEANUTS
}

\section{NIRMALA $A^{1 *}$, PRABASHEELA $B^{2}$ AND NAGALAKSHMI $\mathbf{R}^{3}$}

1, 2: Department of Biotechnology, Aarupadai Veedu Institute of Technology, Vinayaka Missions Research Foundation, Kanchipuram (Dt), Paiyanoor

3: Department of Chemistry, Aarupadai Veedu Institute of Technology, Vinayaka Missions

Research Foundation, Kanchipuram (Dt), Paiyanoor

*Corresponding Author: E Mail: drnirmala81@gmail.com

\section{Received $17^{\text {th }}$ Nov. 2019; Revised $16^{\text {th }}$ Dec. 2019; Accepted $19^{\text {th }}$ Jan. 2020; Available online $1^{\text {st }}$ July 2020}

\section{https://doi.org/10.31032/IJBPAS/2020/9.7.5110}

\section{ABSTRACT:}

Peanut is a legume crop that belongs to the family Fabaceae, botanically named as Arachishypogaea. Peanuts are consumed in many forms such as boiled peanuts, peanut oil, peanut butter, roasted peanuts and added peanut meal in snack food, energy bars and candies. Peanuts are considered as important source of nutrients. These peanut can be easily affected with Filamentous fungi producing toxic secondary metabolites called mycotoxins that may affect the health of the individual's especially in developing countries and where there is a lack of food security, quality and food insufficiency. One such mycotoxin called aflatoxins it is toxic metabolites produced by Aspergillus, which includes the species like A. flavus, A. parasiticus, and $A$. nomius. It is highly toxic and significant risk factor for liver and kidney causes cancer, teratogenicity, under nutrition and micronutrient malabsorption in both animals and humans. The present review focused on one such food of peanut and their composition in terms of essential biomolecules and their biological purposes. It highlights the effectiveness of considering peanuts as a vital component in human diet due to its nutritional values, also deliberates the association between consumption of fungus infected peanuts and their effect on human health and physiology.

Keywords: Peanut, Aflatoxins, Mycotoxins, Secondary metabolites, Aspergillus sps. 


\section{INTRODUCTION}

Peanut or Groundnut belongs to the family Fabaceae. In some part of the world they are known as edible seeds of a legume. Peanuts are supposed to originated in Central American region from where they spread to other parts of the world. They are widely cultivated in China [1] India, Africa, South America, United States [2] and few other countries. In worldwide nearly 300 different varieties of peanuts are grown, which include common varieties like Georgia runner, Tennessee red, Virginia, Valencia, Tennessee white and many other varieties. Peanuts vary in color from red to brown and are usually rough in their presence. Maximum quantity of produced peanut is used for manufacturing of oil. In the year 2000, world production of peanut oil has risen from 4.53 million metric tons to 4.91 in 2010. Worldwide Production across the countries, where China (44\%), Indian $(20 \%)$, and Nigeria $(11 \%)$ are the major manufacturers, is anticipated to account for almost $75 \%$ of the world's peanut oil. Second largest producer of peanut is India, with total production of nearly $7,131,000$ million metric tons per year. Apart from oil production it is extensively used for the preparation of roasted peanuts, peanut butter, snacks product, extenders in meat product formulation and soaps [3].
The history of peanuts years back to the times of ancient Incas of Peru. They are the people were first cultivated the wild variety of peanuts and presented them to the sun God as part of their spiritual formalities. In America, modern history of peanut popularization began with the Civil war in 1860s. George Washington Carver who is known as the father of peanut industry as he developed more than three hundred products derived from the peanut. Propagation and commercialization of peanut butter in America which was progressively spread all over Europe and Asia by Rosen field after he began making of his own brand of peanut butter [4].

The nutritional prominence of peanuts is due to the high energy and growth enhancing constituents present in it. That includes proteins, lipids, carbohydrates, vitamins, minerals, some organic acids and purines. In many countries nearly $30 \%$ of the people suffering from malnutrition [5]. Peanuts contains enormous source of essential amino acids and protein it can help in avoiding malnutrition [6]. Moreover a peanut contains biologically active compounds like alpha tocopherols, phytosterols, Flavonoids, resveratrol which contribute to the valuable properties of peanuts [5]. In the present study focused on nutritional value of peanut and natural 
manifestation of aflotoxins and their health effects.

\section{Peanut as a functional food:}

Many Researches has recognised that, lot of compounds which is present in peanuts and their skins may have additional health benefits beyond their elementary nutrition. Peanuts have been advertised as a functional food with numerous functional components like Coenzyme Q10 which guards the heart during the period of lack of oxygen supply example in high altitudes places. Peanuts are also contain worthy source of dietary fibre and provide a wide range of vital nutrients, including several B group vitamins, vitamin E, minerals such as iron, Zinc, Potassium and Magnesium, antioxidant minerals (selenium, manganese and copper), plus other antioxidant compounds [7].

These bioactive components have capacity to prevent disease and few are antioxidants while other is to promote long life. It contains biologically important matters such as vitamin $E$ in oil or chlorogenic acid, caffeic acid, coumaric acid, ferulic acid, flavonoids and stilbene this will increase the total antioxidant capacity in peanut (resveratrol) $[\mathbf{8}]^{\cdot}$ To find the antioxidant action and free radical scavenging capacity fermented peanut meal is used [9].

\section{Active compounds in peanut:}

\section{Resveratrol:}

Resveratrol (3, 4, 5-trihydroxystilbene) belongs to a class of polyphenolic compounds called stilbenes. It is phytochemical present in grapes and red wine as well as peanut. Resveratrol present in all parts of the peanut including roots, skin and shell [10]. Its content is varying in peanuts and peanut product. Resveratrol belongs to the class of antibiotic compound called as phytoalexins. This phytoalexins is natural product with low molecular mass made by plant for the purpose of defending the plant when the plant gets injured. For example when plant gets affected with fungus resveratrol synthesised from $\mathrm{p}$ coumaroyl CoA and malonyl CoA. Nearly 73 micro grams of resveratrol present in each ounce of peanut. Resveratrol is a fatsoluble compound that occurs in both Trans and Cis configuration. Both Cis- and transresveratrol also occur as glucosides, which have been found to have defensive function against cancers [11] heart disease [12] degenerative nerve disease, Alzheimer's disease, tumour [13] and inflammation [14]. This compound will increase the blood flow in brain as much as and thus reduce the risk of stroke up to $30 \%$ [15]. Moreover it provides protection against cardiovascular diseases such as arteriosclerosis, it has been confirmed that resveratrol acts as chemo preventive agent 
in contradiction of several types of cancer elevation and development phases [16]

by controlling initiation of tumour, Figure 1.

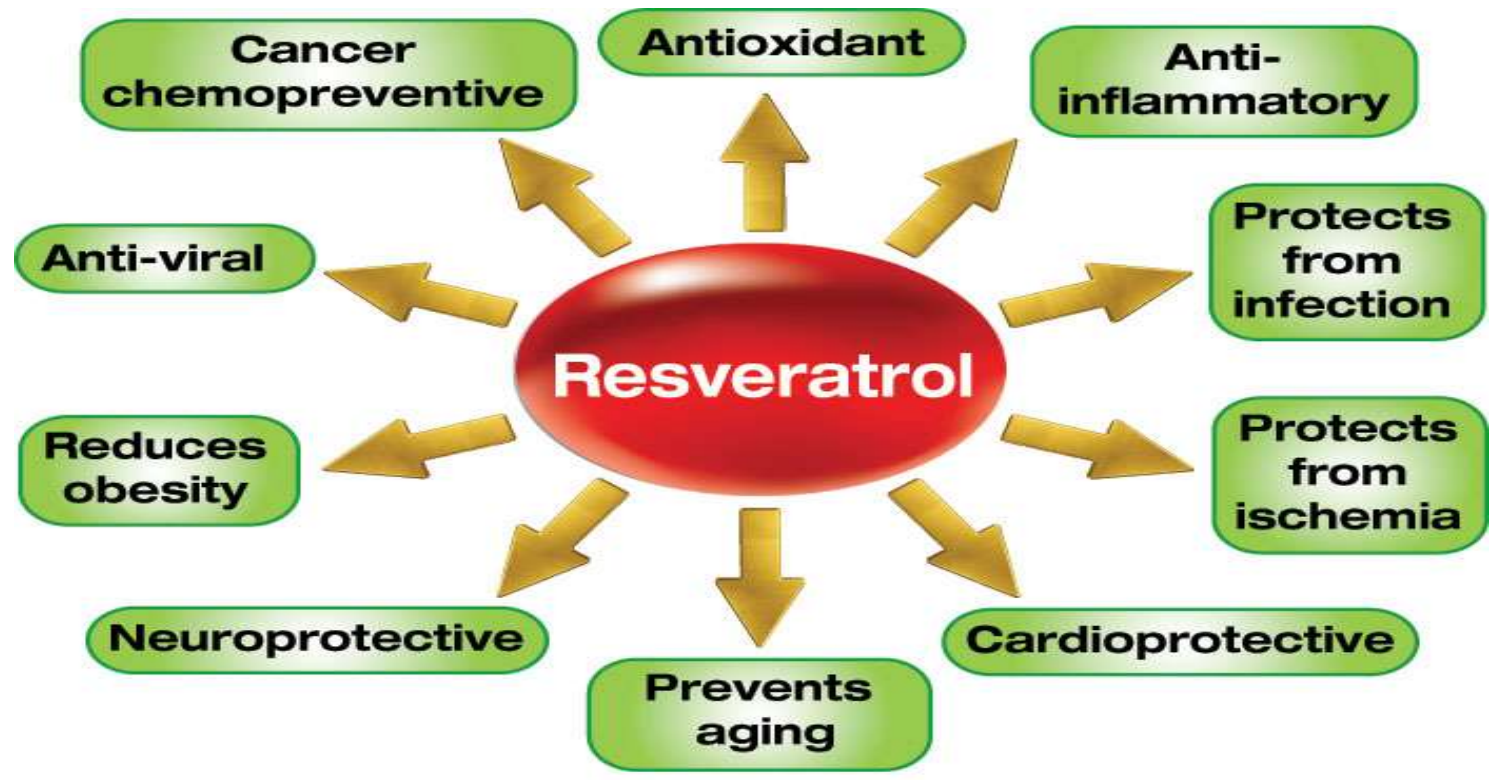

Figure 1: Health Benefits of Resveratol

Sources of resveratrol:

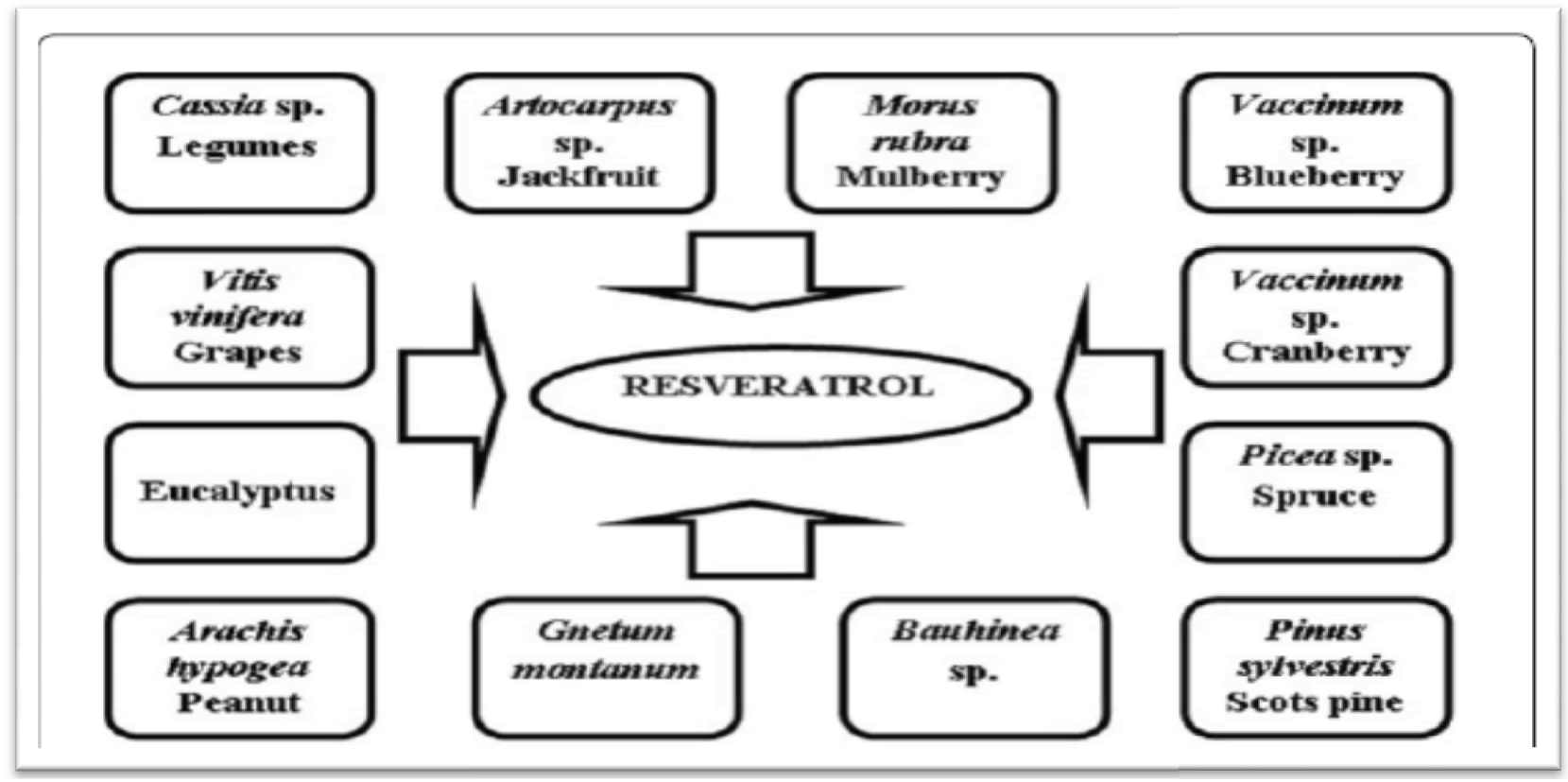

Figure 2: Sources of Resveratol

Resveratrol role in cardiovascular disease:

It is an effective anti-oxidant [17, 18] it inhibits the lipid peroxidation of LDL, inhibit the cytotoxicity effect of oxidized LDL thus it retains the cell against lipid peroxidation. It is highly hydrophilic and lipophilic nature, since it provides more effect on free radicals than the other well-known antioxidants like vitamin $\mathrm{C}$ and 
E. Further it helps in prevention of atherosclerosis $[\mathbf{1 9}, \mathbf{2 0}]$. Ferrero et al., in their study found that even with small amount of resveratrol had good effect on granulocyte and monocyte adhesion to arterial cell wall; it is more important factors in the beginning of atherogenesis [21].

\section{Resveratrol role in cancer prevention:}

Many scientific studies reported that resveratrol play significant role in prevention of tumour growth. In rat it was detected that resveratrol act as effective antioxidant in inhibiting the free radicals formation and act as anti-mutagenic agent (Figure 3). In another research findings observed the precise effect of resveratrol in two to three stages of carcinogenesis, promotion and progression. It plays a major role in prevention of cyclooxygenase and hydro peroxidase activity which could play a specific role in promotion of tumour cell growth through inflammation and activation of carcinogens [22]. Wolter et al., conducted a study on effect of resveratrol in adenocarcinoma cells. They found that, resveratrol restricted the cell growth at certain point in cell cycle, especially S to G2/ M phase, it also control the level of protein used to imbibe impaired cell growth and tumoarogenesis [23].

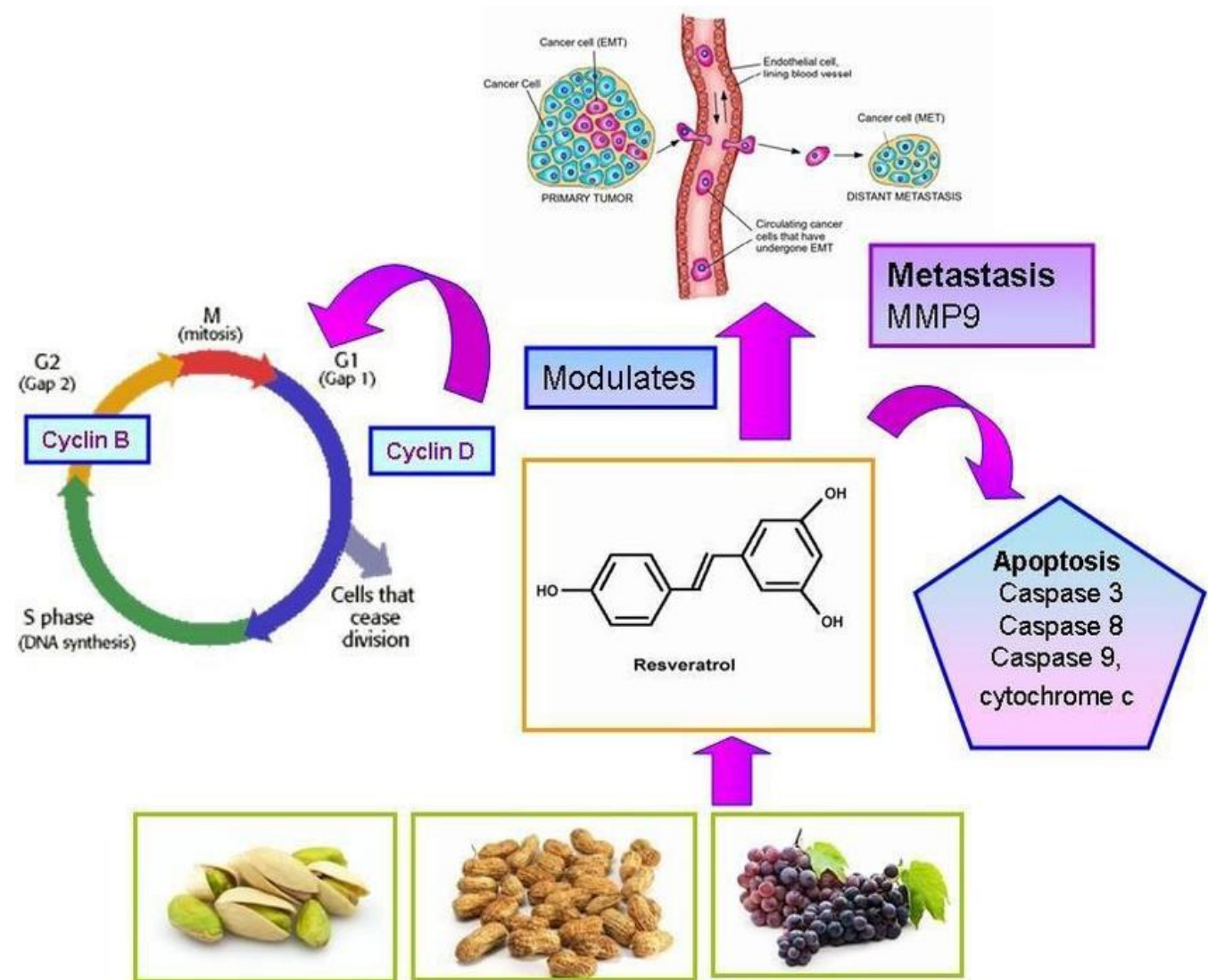

Figure 3: Resveratrol act as effective antioxidant 


\section{Phytosterols in peanut:}

Phytosterols are a group of naturally occurring compounds found in plant cell wall. Because phytosterols are physically similar to the body's cholesterol, when they are consumed they compete with cholesterol for absorption in digestive system. As a result, cholesterol absorption is blocked and blood cholesterol levels reduced. Regular intake of phytosterol with recommended quantity can reduce the total cholesterol up to $10 \%$ and thus decrease the risk of cardiovascular disease. Peanut, peanut butter and peanut oil filled with phytosterol this will prevent the absorption of cholesterol from the diet [24]. Many recent research is showing that it also reduce the inflammation and reduction in growth of various cancers i.e. lung, stomach, ovarian, prostrate, colon and breast cancer [25]. In peanut addition to healthy fats, proteins and fibers, phytosterols may also control the risk of heart disease that has been noticed in people who are taking peanut every day [26].

\section{Phenolic acids and flavonoids in peanut:}

Many research findings clearly shows that peanut and their skin are exceptional source of functional compounds that includes phenolic acid [10]. Peanuts contains higher concentrations of polyphenolic antioxidants, primarily in p-coumaric acid levels, boosting it overall antioxidant content by as much as $22 \%$ [27]. They also further expounded that roasted peanut skin has better antioxidant capacity than the roasted whole peanut. Lopes et al., have also described the role of phenolic acids as antioxidant with all part of peanut contains Flavonoids. A greater consumption of flavonoids is thought to be defensive against heart disease and cancer by various mechanisms [24].

\section{Arginine content in peanut and their uses:}

Highest level of arginine present in peanut among other foods. L-arginine or Arginine is an amino acid that is essential to retain normal liver, skin and joints, strengthen the immune system, regulate hormone levels, sustains normal blood sugar level and encourages male fertility. Several current researches reported that this amino acid improve circulation and used to treat heart disease. In addition, other research has shown that this amino acid has focused on treatment of AIDS, cancer and other diseases linked to a depressed immune system. It helps in liver detoxification by neutralizing the effects of ammonia and other toxic substances in the body [28].

\section{Antioxidants activity of peanut:}

Free radicals are an atom or molecule that bears an unpaired electron and is extremely reactive, capable of 
attractive in rapid changes in reaction that interrupt with other molecules and create many more free radicals. Free radicals paly a fundamental role in aetiology of several disease like cancer, arthritis. The oxidative damage to DNA may play important role in aging and presence of intracellular oxygen is accountable to initiate a chain of unintentional changes at the cellular level and these changes may causes dangerous effect on biomolecules [29].

Antioxidants are group of substances comparatively present at low concentrations, in relation to oxidizable substrates, significantly inhibit or delay oxidative processes, while often being oxidized themselves and thus have diverges physiological role in the body [30]. The free radical-scavenging activity of the peanut skin was comparable with that of other natural antioxidants. Other inhibitory activities, such as reducing power, inactivation of hydroxyl or superoxide radicals, were satisfactory. Peanut skin extracts may thus be a potential source of natural antioxidants [31], and it had a good free radical - scavenging activity, equal to that of synthetic antioxidants like Butylatedhydroxyanisole (BHA) [32].

HEALTH BENEFITS OF PEANUT:

\section{Diabetes and Inflammation}

Jiang et al., reported that people who takes a peanut in their daily diet, getting reduced risk of diabetes [33]. It contains extraordinary source of dietary fibres, magnesium have been attributes as the main influential factors for improved health status $[34,35]$. Inflammatory factors in the blood like C-reactive proteins (CRP) have been identified as predictors of cardiovascular disease. Dietary factors may play a role in reducing inflammation [36]. For regulation of inflammation antioxidants, certain fats, dietary fibre, arginine, and magnesium are important components present in peanut [37].

\section{Gallstone Disease and Alzheimer's:}

Peanut is excellent source of niacin and vitamin $\mathrm{E}$, both have protective effect against Alzheimer's disease and age-related cognitive decline. Nearly 4000 people (65 years old) was observed that niacin from food slow down the rate of cognitive decline [38]. It has also been found that the intake of vitamin E from supplements had no effect on the incidence of Alzheimers, but vitamin $\mathrm{E}$ intake from food has been protected (Morris 2002). It has been observed that, the person who takes peanut and peanut butter five times in a week or more have a reduced risk of gallbladder disease nearly $25 \%$ [39].

\section{Cancer:}

Peanut containing certain vitamins, minerals, unsaturated fats and their bioactive components shown to have cancer-preventive effects [40]. In facts, the phytosterols in peanuts that have been 
studied in regards to cancer [25], they have been reported that $40 \%$ of reduction in prostrate tumor growth and $50 \%$ decline in the cancer spreading to other parts of the body [26]. Similar to phytosterols, resveratrol has also been inhibiting the cancer cell growth by deadline the blood supply to growing cancers cell [41].

\section{HEALTH ISSUES RELATED TO PEANUT CONSUMPTION:}

\section{Aflatoxins:}

Aflatoxins are amongst the most poisonous mycotoxins and are produced by certain moulds, that are naturally present all over the world. It can contaminate easily with food crops and causes serious health hazards to humans and other livestock's. Aflotoxins are produced by two closely related fungi like Aspergillus flavus and A. parasiticus $[\mathbf{4 2}, \mathbf{4 3}]$. Nearly more than 14 types of Aflotoxins occurs in nature but only four types like B1, B2, G1 and G2 are mainly dangerous to human and animals as they found in all food crops. It may get affect before and after harvesting the crops and improper storage condition that favour the growth of mould can typically lead to high level of contamination than those found in the field [44]. The International Agency for Research on Cancer (IARC) has classified aflatoxin B1 as a Group 1 human carcinogen [45].
Aflatoxins and serious health consequences:

Long-standing or chronic exposure to aflatoxins has several health concerns including conversion of aflatoxin to a reactive metabolite such as aflatoxin-8,9epoxide in the liver appears to be accountable for many of its toxic effects [46].

- Aflatoxins are dominant carcinogens and may affect all organ systems, particularly the liver and kidneys; they cause liver cancer and have been linked to other types of cancer - AFB1 is known to be carcinogenic in humans; the potency of aflatoxin to cause liver cancer is significantly increased in presence of infection with hepatitis $\mathrm{B}$ virus (HBV).

- Aaflatoxins are mutagenic substance in bacteria (affect the DNA), genotoxic and have the potential effect to cause birth defects in children.

- Children may become underdeveloped, although these data have yet to be confirmed because other factors also underwrite to growth faltering e.g. low socioeconomic status, chronic diarrhoea, malnutrition; infectious diseases [47-55]. 
- Aflatoxins may cause immunosuppression, therefore may decrease resistance to infectious agents like HIV, Tuberculosis [5556].

\section{Peanut allergies:}

The exact reason of the allergy is unknown. Subsequently terms of peanuts allergy are connected to the action of immunoglobulin $\mathrm{E}$ (IgE) and other anaphylatoxins, which act to release histamine and other mediator substances from mast cells (degranulation). Also other side effects like it induce the vasodilation and construction of bronchioles in lungs, known as bronchispasm. The Symptoms and signs of an allergic response to peanuts as follows

- Runny nose

- Tightening of the throat

- Digestive problems, such as diarrhea, vomiting or nausea

- Tingling in the mouth and throat

- Skin reactions, such as itching, hives, redness or swelling

- Shortness of breath or wheezing [57].

\section{Peanuts and food poisoning:}

Peanuts are normally contaminated by the fungal species of Aspergillus flavus, which can produce the aflatoxin. During transportation and storage this infection can occurs in peanut. Aflatoxins are highly toxic and carcinogenic secondary metabolites of concern in food safety infection and aflatoxin concentration in peanut can be associated with soil moisture stress during pod-filling when soil temperatures are near suitable for $A$. flavus. This contamination will cause a food poisoning effect [58].

\section{CONCLUSION:}

Peanuts are tremendous and inexpensive source of nutrition, supplementing vital nutrients to the human body. Peanuts are as widespread as they are healthy. They are considered as an excellent plant-based source of protein and are high in various vitamins, minerals and plant compounds which helped in the stoppage of non-communicable diseases such as CVD and obesity. However, despite the good nutritional and beneficial properties of peanuts, the presence of peanut allergens confers serious health risk to peanut allergic individuals. Peanuts are frequently mentioned as poor man's protein but, when taken in acceptable amounts.

Aflatoxins are not entirely killed when peanuts are processed or roasted, so it can be a concern even in processed products such as peanut butter. Soaking, sprouting or fermenting peanuts can help lower the presence of mould. Buy only renowned viable brands of peanuts can discard nuts contaminated with mould, discoloured or shrivelled. A diet with peanuts could deliver all these energetic 
nutrients, and play a critical role in preventing disease and promoting good health.

\section{REFERENCES}

[1] Yao G, Peanut Production and Utilization in the People's Republic of China. 2004.

http://www.caes.uga.edu/commoditi es/fieldcrops/peanuts/pins/document s/ChinaProduction.pdf

[2] Tom DD, Earliest-Known Evidence of Peanut, Cotton and Squash Farming Found. 2007. http://www.eurekalert.org/pub_relea ses/2007-06/vu-eeo062507.php

[3] Rustom IYS, Lopez-Leiva MH, Nair BM, Nutritional, sensory and physicochemical properties of peanut beverage sterilized under two different UHT conditions. Food Chem, 56, 1996, 45-53.

[4] Carver GW, How to grow the peanut and 105 ways of preparing it for human consumption. Tuskegee Institute Experimental Station Bulletin 31, Alabama, 1925.

[5] FAO, The spectrum of Malnutrition, 2000. http://www.fao.org/worldfood summit/english/fsheets/malnutrition .pdf

[6] Pelto GH, Armar-Klemesu M, Balancing Nurtur-ance, Cost and Time: Complementary Feeding in
Accra, Ghana. Maternal \& Child Nutrition, 7(3), 2011, 66-81.

[7] Geulein I, Antioxidant properties of resveratrol: a structure activity insight. Innov Food Sci Emerg Technol, 11, 2010,210-218.

[8] Yu JM, Ahmedna M, Goktepe I, Dai J, Peanut skin procyanidins: composition and antioxidant activities as affected by processing. J Food Compos Anal, 19, 2006, 364-371.

[9] Zhang Y, ZhangH, Wang L, Guo X, Qi X, Qian H, Influence of the degree of hydrolysis (DH) on antioxidant properties and radical scavenging activities of peanut peptides prepared from fermented peanut meal. Eur Food Res Technol, 232, 2011, 941-950.

[10] Francisco ML, Resurreccion AV, Functional components in peanuts. Crit Rev Food Sci Nutr, 48(8), 2008, 715-746.

[11] Gagliano N, Aldini G, Colombo G, Rossi R, Colombo R, Gioia M, Milzani A, Dalle Donne I, The potential of resveratrol against human gliomas. Anti-Cancer Drug, 21, 2010, 140-150.

[12] Juan ME, Vinardell MP, Planas JM, The daily oral administration of high doses of trans-resveratrol to rats for 28 days is not harmful. 
The J Nutr, 132(2), 2002, 257260.

[13] Bishayee A, Polities T, Darvesh AS, Resveratrol in the chemoprevention and treatment of hepatocellular carcinoma. Cancer Treat Rev, 36, 2010, 43-53.

[14] Kang L, Heng W, Yuan A, Baolin L, Fang H, Resveratrol modulates adipokine expression and improves insulin sensitivity in adipocytes relative to inhibition of inflammatory responses. Biochemie, 92, 2010,789.

[15] FazelNabavi S, Li H, Daglia M, Mohammad Nabavi S, Resveratrol and stroke: from chemistry to medicine. Curr Neurovasc Res, 11(4), 2014, 390-397.

[16] Delmas D, Lançon A, Colin D, Jannin B, Latruffe N, Resveratrol as a chemo preventive agent: a promising molecule for fighting cancer. Curr Drug Targets, 7(4), 2006, 423-442.

[17] Frankel EN, water house AL, Kinsella JE, Inhibition of human LDL oxidation by resveratrol, Lancert, 341, 1993, 1103-1104.

[18] Chanvitayapongs S, Draczyskalusiak, Sun AY, Amelioration of oxidative stress by antioxidant and resveratrol in
PC12 cells, Neruroreport, 8, 1997, 1499-1502.

[19] Soleas GJ, Diamandis EP, Glodberg DM, Resveratrol: A molecule whose time has come and gone, ClinBiochem, 30, 1997, 91-113.

[20] Rotondo S, Rajtar G, Manarini S, Celardo A, Rotilio D, De Gaetano G, Evangelista V ,Cerletti C, Effect of trans -resveratrol a natural polyphenolic compound on human polymorphonuclear leukocyte function, British J. Pharmacol, 123, 1998, 1691-1699.

[21] Ferrero ME, Bertelli AAE, Fulgenzi A, Pellegatta F, Corsi MM, Bonefrate M, Ferrara F, Caterina RD, Giovannini $\mathrm{L}$ and Bertelli A, Activity In vitro of resveratrol on granulocyte and monocyte adhesion to endothelium. Am J Clin. Nutri, 68, 1998, 1208-1214.

[22] Jang M, Cai L, Udeani GO, Slowing KV, Thomas CF, Beecher CWW, Fong HHS, Farnsworth NR, Kinghorn AD, Mehta RG, Moon RC, Pezzuto JM, Cancer chemo preventive activity of resveratrol a natural product derived from grapes, Science, 275, 1997, 218-220. 
[23] Wolter F, Akoglu B, Clausnitzer A, Stein J, Down regulation of the cyclin $\mathrm{D} 1 / \mathrm{Cdk}_{4}$ complex occur during resveratrol induced cell cycle arrest in colon cancer cell lines J Nutr, 131, 2001, 2197 2203.

[24] Lopes RM, Agostini-Costa TDS, Gimenes MA, Silveira D, Chemical composition and biological activities of Arachis species. J Agri Food Chem, 59(9), 2011, 4321-4330.

[25] Woyengo TA, Ramprasath VR, Jones PJ, Anticancer effects of phytosterols. Eur J Clin Nutr, 63(7), 2009, 813-820.

[26] AwadAB, Chan KC, Downie AC, Fink CS, Peanuts as a source of $\beta$ sitosterol, a sterol with anticancer properties. Nutr Cancer, 36(2), 2000, 238-241.

[27] Duncan CE, Gorbet DW, Talcott ST, Phytochemical content and antioxidant capacity of watersoluble isolates from peanuts (Arachishypogaea L.). Food Res Int, 39(8), 2006, 898-904.

[28] Moncada S, Higgs A,The Larginine-nitric oxide pathway. $\mathrm{N}$ Engl J Med, 329, 1993, 20022012.

[29] Gordon M, The developments of oxidative rancidity in foods. In $\mathrm{J}$
Pokorny N. Yanishlieva, M. Gordon (Eds.) Antioxidants in food and practical applications 2001. Pp 21-22.United Kingdom: CRC press, Wood- head publishing Ltd.

[30] Vaya J, Aviram M. Nutritional antioxidants: mechanism of action, analyses of activities and medical application. Nutrition, 49, 1999, 17.

[31] Cabrini L, Barzanti V, Cipollene M, Fiorentini D, Grossi G, Tolomelli B, Zamboni L, Antioxidants and total peroxyl radical-trapping ability of olive and seed oils. Journal of Agricultural and Food Chemistry, 49, 2001, 6026-6032.

[32] Seung EL, Chang HP, Jin KB, Nak SS, Tae YC. Comparison of antioxidant potential of several peanut varieties. Journal of Korean Society of Food Science and Nutrition 2004; 33: 941-945.

[33] Jiang R, Wang M, Davis S,Nut and peanut butter consumption and risk of type 2 diabetes in women. J Am Med Assoc, 288(20), 2002, 2554-2560.

[34] King DE, Mainous III AG, Geesey ME, Ellis T, Magnesium intake and serum $\mathrm{C}$ reactive protein 
levels in children. Magnesium Res, 20(1), 2007, 32-36

[35] Gartside PS, Wang P, Glueck CJ, Prospective assessment of coronary heart disease risk factors: the NHANES I epidemiologic follow- up study (NHEFS) 16-year follow-up. J Am Coll Nutr, 17(3), 1998, 263-269.

[36] Nettleton JA, Steffen LM, MayerDavis EJ, Jenny NS, Jiang R, Herrington DM, Jacobs D. Dietary patterns are associated with biochemical markers of inflammation and endothelial activation in the Multi-Ethnic Study of Atherosclerosis (MESA). Am J Clin Nutr, 83(6), 2006, 1369-1379.

[37] Salas-Salvadó J, Casas-Agustench P, Murphy MM, López-Uriarte P, Bulló M, The effect of nuts on inflammation. Asia Pac J Clin Nutr, 17(Suppl1), 2008, 333-336.

[38] Morris MC, Dietary niacin and the risk of incident alzheimer's disease and of cognitive decline. J Neurol Neurosurg Psychiatry, 75(8), 2004, 1093-1099.

[39] Tsai CJ, Leitzman MF, Hu FB, Willett WC, Giovannucci EL, Frequent nut consumption and decreased risk of cholecystectomy in women. Am J Clin Nutr, 80(1), 2004, 76-81.

[40] Gonzalez CA, Salvado JS, The potential of nuts in the prevention of cancer. Br J Nutr, 96, 2006, S87-S94.

[41] FazelNabavi S, Li H, DagliaM, Mohammad Nabavi S, Resveratrol and stroke: from chemistry to medicine. Curr Neurovasc Res, 11(4), 2014, 390-397.

[42] Bennett JW, Klich M, Mycotoxins. ClinMicrobiol Rev, 16, 2003, 497-516.

[43] Reddy KRN, Salleh BB, Saad HK, Abbas CA, Abel WT, Shier, An overview of mycotoxin contamination in foods and its implications for human health. Toxin Rev, 29, 2010, 3-2.

[44] Katerere DR, Shepard GS, Faber $\mathrm{M}$, Infant malnutrition and chronic aflatoxicosis in Southern Africa: is there a link? Int $\mathrm{J}$ Food Saf Nutr Public Health, 1, 2008, 126-136.

[45] World Health Organization; International Agency for Research on Cancer. Some naturally occurring substances: Food items and constituents, heterocyclic aromatic amines and mycotoxins. In IARC Monographs on the Evaluation of the Carcinogenic Risk of Chemicals to Humans; 
World Health Organization:

Geneva, Switzerland, Volume 56, 1993, 100-110.

[46] Eaton DL, Gallagher EP, Mechanisms of aflatoxin carcinogenesis. Annu Rev Pharmacol. Toxicol, 34, 1994, 135-172.

[47] Gong Y, Hounsa A, Egal S, Turner PC, Sutcliffe AE, Hall AJ, Cardwell K, Wild CP, Post weaning exposure to aflatoxin results in impaired child growth: A longitudinal study in Benin, West Africa. Environ. Health Perspect, 112, 2004, 1334-1338.

[48] Jiang Y, Jolly PE, Ellis WO, Wang JS, Phillips TD, Williams JH,Aflatoxin B1 albumin adduct levels and cellular immune status in Ghanaians. Int. Immunol, 17, 2005, 807-814.

[49] Khlangwiset P, Shephard GS, Wu, Aflatoxins and growthimpairment: A review Crit Rev Toxicol, 41, 2011, 740-755.

[50] Mahdavi R, Nikniaz L, Arefhosseini SR, VahedJabbari M, Determination of aflatoxin $\mathrm{M}(1)$ in breast milk samples in Tabriz-Iran. Mater Child Health J.14, 2010, 141-145.

[51] Okoth SA, Ohingo M, Dietary aflatoxin exposure and impaired growth in young children from Kisumu District, Kenya: Cross sectional study. Afr J Health Sci, 11, 2004, 43-54.

[52] Sadeghi N, Oveisi M, Jannat B, Hajimahmoodi $\mathrm{M}$, Bonyani $\mathrm{H}$, Jannat, F, Incidence of aflatoxin M 1 in human breast milk in Tehran, Iran. Food Control, 20, 2009, 7578.

[53] Shuaib FM, Jolly PE, Ehiri JE, Yatich N, Jiang Y, Funkhouser E, Person SD, Wilson C, Ellis WO, Wang JS, Association between birth outcomes and aflatoxin B1 biomarker blood levels in pregnant women in Kumasi, Ghana. Trop Med Int Health, 15, 2010, 160167.

[54] Turner PC, Moore SE, Hall AJ, Prentice AM, Wild CP. Modification of immune function through exposure to dietary aflatoxin in Gambian children. Environ Health Perspect, 111, 2003, 217-220.

[55] Williams JH, Phillips TD, Jolly PE, Stiles JK, Jolly CM, Aggarwal D, Human aflatoxicosis in developing countries: A review of toxicology, exposure, potential health consequences, and interventions. Am J Clin Nutr, 80, 2004, 1106-1122. 
[56] Wild CP, Hall AJ, Primary hepatocellular carcinoma in developing countries. Mutat Res, 462, 2000, 381-393.

[57] Anderson JA, Allergic reactions to foods. Crit Rev Food Sci Nutr, 36(S), 1996, S19-S38.

[58] Achar PN, Hermetz K, Rao $\mathrm{S}$, Apkarian $\quad \mathrm{R}$, Taylor $\quad \mathrm{J}_{2}$ Microscopic studies on the Aspergillus flavus infected kernels of commercial peanuts in Georgia. Ecotoxicol Environ Saf, 72, 2009, 2115-2120. 